\title{
Crohn's disease in Bangladeshis and Europeans in Britain: an epidemiological comparison in Tower Hamlets
}

\author{
C.S.J. Probert, V. Jayanthi, D.J. Pollock ${ }^{1}$, S.I. Baithun, ${ }^{1,2}$ J.F. Mayberry and \\ D.S. Rampton ${ }^{1}$
}

Leicester General Hospital, Leicester, ${ }^{1}$ Royal London Hospital, Whitechapel, London and ${ }^{2}$ St Andrew's Hospital, Bow, London, UK

\begin{abstract}
Summary: The incidence of Crohn's disease in a defined Bangladeshi community was assessed in a retrospective, epidemiological study in the London Borough of Tower Hamlets from 1972 to 1989. The borough population of 164,000 includes over 28,000 Bangladeshis. Potential cases were identified from hospital pathology and medical records. There were 99 cases of Crohn's disease during the study period, of which five were Bangladeshi. The mean standardized incidence in Bangladeshis was $1.2 / 10^{5} /$ year in the 1970 s and $2.3 / 10^{5} /$ year in the 1980 s compared with $3.8 / 10^{5} /$ year and $4.1 / 10^{5} /$ year in Europeans, and $4.6 / 10^{5} /$ year and $5.4 / 10^{5} /$ year in West Indians, respectively. None of the changes with time was statistically significant. There were no cases amongst Hindus. The relative risk to Europeans, compared to Bangladeshis, was 2.5 during the 1970s and 2.0 in the 1980s. The difference between European incidence and that of other ethnic groups was not statistically significant; however, the number of Bangladeshi cases was small (five), and diminishes the power of the study. The apparent similarity of the incidences of Crohn's disease in Bangladeshis and Europeans contrasts with findings in other South Asians. Further investigations of the differences in incidence of Crohn's disease in South Asians is needed.
\end{abstract}

\section{Introduction}

Epidemiological studies have shown marked regional variation in the incidence of Crohn's disease (CD). ${ }^{1-19}$ There are few reliable data about inflammatory bowel disease (IBD) in Asia, ${ }^{19,20}$ where $C D$ appears to be rare. Little is known about CD in Bangladesh but it appears to be less common there than ulcerative colitis. ${ }^{21}$ Studies of IBD in migrants to Britain ${ }^{3,22-27}$ suggest that $C D$ is less common in West Indians ${ }^{22}$ and people whose families who originated in the Indian subcontinent (South Asians) ${ }^{28,29}$ than in the European population. ${ }^{23-25}$ The incidence of CD in Bangladeshis in Britain has not been studied previously.

Tower Hamlets is a borough in the East End of London. It has been a transition zone ${ }^{30}$ for migrants for centuries; French Huguenots, Irish and European Jews were followed by Bangladeshis. Since the 1970s, there has been a substantial migration from the Sylhet district of Bangladesh, because of economic and social deprivation, partition and the war between East and West Pakistan. Approximately $20 \%$ of Bangladeshis in Britain live in Tower Hamlets making it the largest Bangladeshi community in the country. ${ }^{31}$

Correspondence: C.S.J. Probert, M.R.C.P., University of Bristol, Department of Medicine, Bristol Royal Infirmary, Bristol BS2 8HW, UK.

Accepted: 2 April 1992
Comparison of the incidence of Crohn's diseaseo in different ethnic groups living in the same geographical area may cast light on its aetiology. The aim of this study was to determine the epidem-응 iology of Crohn's disease in Bangladeshis and $\stackrel{2}{ }$ Europeans in Tower Hamlets.

\section{Patients and methods}

Sources of cases

The study was performed retrospectively to cover the period from 1 January 1972 to 31 Decembero 1989. Tower Hamlets is served by one health authority and patients are treated in branches of 5 the Royal London Hospital at Whitechapel and Mile End. The case notes of patients treated at the Bethnal Green branch, which has closed, are still available. Some patients from the east of the borough (Bow) are treated in St Andrew's Hospital, run by the neighbouring Newham Health $\omega$ Authority. Potential cases were identified frome hospital activities analysis and Korner data frome Tower Hamlets Health Authority, and from records held in the pathology departments of the ${ }^{-}$ Royal London and St Andrew's Hospitals. People ${ }_{T}^{T}$ from Tower Hamlets referred to St Mark's Hos- $\frac{\text { Oे }}{\mathrm{D}}$ pital, in City and Hackney Health Authority, were $\frac{\rho}{\mathbb{Q}}$ 
identified from a computerized index of patients with IBD. General practitioners in the borough were also approached to identify cases. Case notes and microfiche records were obtained for all candidate cases.

Demographic details and the results of laparotomies, histopathological, microbiological, radiological and endoscopic investigation were noted. Demographic details were checked with family doctors where case notes were incomplete. All candidate cases were reviewed, using a structured proforma (Appendix 1) based on Lennard-Jones' criteria of case definition, ${ }^{32}$ by two of the authors (V.J. and C.S.J.P.), for whom inter- and intraobserver variation had been assessed previously. ${ }^{26}$ A strict scoring system was not applied, but characteristic features were sought from investigations recorded in the case-notes and used to classify the candidate patients as cases or non-cases. Patients in whom the diagnosis of CD was entirely clinical were excluded. Patients with ulcerative colitis or tuberculous enteritis were reported separately. ${ }^{27,33}$ Patients with indeterminate colitis or inflammation secondary to infection, ischaemia or radiation were excluded. Only patients diagnosed whilst residing in the borough were included. Data of definite diagnosis were used for incidence calculations.

Over 2,800 potential cases of IBD were scrutinized. Most were people resident outside the borough, but treated at the Royal London Hospital. A few cases of miscoding arose largely from discussions about the differential diagnosis of irritable bowel syndrome, ischaemic colitis and diverticular disease.

Ethical Committee approval was given for the study.

\section{Sources of demographic data}

The migration discussed above and the slum clearance of the 1970s resulted in marked demographic changes in the borough. The population in 1971 was $164,650^{34}$ but fell after the slum clearance. The European population was 114,530 in $1981,{ }^{35}$ but increased towards the end of the decade, following an urban renewal policy and Docklands development. In 1971 there were 3,560 Pakistanis, ${ }^{34}$ mainly Bangladeshis and, by 1981, 12,596 Bangladeshis. ${ }^{35}$ Migration from other parts of Britain and Bangladesh, and the high birth rate has led to the growth of this community. Estimates from a variety of sources have been used for this and parallel studies: ${ }^{27,33}$ London Research Centre (LRC) $^{36}-23,345$ (1986); Office of Population Censuses and Surveys (OPCS) ${ }^{30}-18,000$ (1987); and LRC-34,627 (1991). The Bangladeshi population of 1989 was calculated from these three sources as follows: the arithmetic mean of the 1986 (LRC) and
1987 (OPCS) estimates were calculated, then the mean of this and the 1991 (LRC) gave an estimate of the Bangladeshi population in 1989 of 27,674. The age structure of the Bangladeshi community in the Borough was found by applying national estimates of the Bangladeshi population age structure $^{37}$ were applied to OPCS data (1981) and our 1989 estimate.

There is only one estimate of the Jewish population in the Borough-7,500 in 1985 (Board of Deputies, personal communication).

\section{Statistical methods}

Data were analysed using a modification of Cochran's test to compare standardized incidences, ${ }^{38} \chi^{2}$ test, relative risk for population studies ${ }^{39}$ age standardized incidence using the direct method ${ }^{40}$ and $95 \%$ confidence intervals. ${ }^{39}$ Confidence intervals were calculated using Confidence Interval Analysis software. ${ }^{39}$

\section{Results}

There were 99 cases of Crohn's disease, two of indeterminate colitis and 196 of ulcerative proctocolitis (described elsewhere). ${ }^{27}$

\section{Incidence}

From 1972 to 1980 there were 45 cases of CD. Of these, 42 were European, two West Indian and one Bangladeshi. The age-standardized incidence in Europeans was not significantly different from that in Bangladeshis $(Z=0.6, \mathrm{NS})$ (Table I, Figure 1). The relative risk to Europeans was $2.5(95 \%$ confidence interval (CI) $0.3-18$ ). There was no difference between the standardized incidence in Europeans and West Indians $(Z=0.45$, NS), the relative risk to West Indians being $1.4(95 \% \mathrm{CI}$ 0.3-5.7).

From 1981 to 1989 , there were 54 new cases of CD; 45 were Europeans (of whom three were Jewish), four were Bangladeshi, three were West Indian, and two non-Bangladeshi Muslims. The incidence of CD tended to increase with time in each ethnic group, although not significantly: Europeans $\left(\chi^{2}=1.4\right.$, NS), Bangladeshis $\left(\chi^{2}=0.2\right.$, NS), and West Indians $\left(\chi^{2}=0.8, N S\right)$. The standardized incidence in Europeans was not significantly different from that of Bangladeshis $(Z=0.5$, NS; relative risk $2,95 \% \mathrm{CI} 0.7-5.5$ ), or West Indians $(Z=0.06, \mathrm{NS}$; relative risk $1.04,95 \% \mathrm{CI} 0.3-3.3)$. A comparison of mean crude incidence in Jews, for whom the age distribution in Tower Hamlets is not known, with other Europeans was also insignificant $(Z=0.01$, NS; relative risk $1,95 \%$ $0.3-3.2$ ). 
Table I Cases and standardized incidence and cases (100,000/year) of Crohn's disease in Tower Hamlets

\begin{tabular}{|c|c|c|c|c|c|}
\hline Year & $\begin{array}{l}\text { European } \\
\text { Christians }\end{array}$ & Jews & $\begin{array}{l}\text { Bangladeshi } \\
\text { Muslims }\end{array}$ & $\begin{array}{c}\text { Other } \\
\text { Muslims }\end{array}$ & $\begin{array}{c}\text { West } \\
\text { Indians }\end{array}$ \\
\hline \multicolumn{6}{|l|}{1972} \\
\hline 1973 & 3 & & 1 & & \\
\hline 1974 & 4 & & & & \\
\hline 1975 & 3 & 2 & & & \\
\hline 1976 & 8 & 1 & & & \\
\hline 1977 & 6 & & & & \\
\hline 1978 & 7 & 1 & & & \\
\hline 1979 & 2 & & & & 2 \\
\hline 1980 & 5 & & & & \\
\hline \multicolumn{6}{|l|}{ Mean } \\
\hline incidence & 3.8 & No & 1.2 & No & 4.6 \\
\hline$(1972-80)$ & & denominator & & denominator & \\
\hline \multicolumn{6}{|l|}{ interval } \\
\hline 1981 & 9 & 1 & & & \\
\hline 1982 & 5 & & & & \\
\hline 1983 & 2 & & 1 & & 1 \\
\hline 1984 & 5 & & & 2 & 1 \\
\hline 1985 & 5 & & 2 & & \\
\hline 1986 & 8 & 1 & & & 1 \\
\hline 1987 & 2 & & & & \\
\hline 1988 & 3 & 1 & & & \\
\hline 1989 & 3 & & 1 & & \\
\hline \multicolumn{6}{|l|}{ Mean } \\
\hline incidence & 4.4 & $4.4^{*}$ & 2.3 & No & 3.6 \\
\hline Confidence & $3.2-5.7$ & $1.6-4.4$ & $0.7-3.7$ & denominator & $0-8.6$ \\
\hline interval & & & & & \\
\hline
\end{tabular}

The standardised incidence of Crohn's disease was similar in each ethnic group. The change in incidence from 1970s to the 1980s was not significant. *Incidence in Jews is crude.

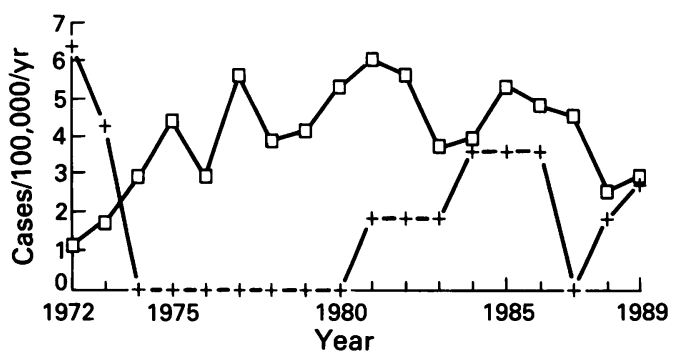

Figure 1 Standardized incidence of Crohn's disease in Tower Hamlets in Bangladeshis ( + ) and Europeans ( $\square$ ). The incidence was calculated for each ethnic group for each year of the study. The rolling incidence, shown on the graph, was found using the mean incidence over 3 year periods, for example, the value for ' 1976 ' was calculated from 1975-1977 and '1977' from 1976-1978.
The standardized incidence in Bangladeshis was also calculated using the population estimates given by LRC and OPCS alone. The LRC projection yielded an incidence of $1.9 / 10^{5} /$ year and OPCS $2.4 / 10^{5} /$ year.

\section{Standardized incidence}

The mean standardized incidence of CD in Europeans from $1972-1989$ was 4.1 cases $/ 10^{5} /$ year. The mean standardized incidence in Bangladeshis was 1.73 cases $/ 10^{5} /$ year.

\section{Sex ratio and age-specific incidence}

During the 1970s the risk of CD amongst European men and women was similar (relative risk $1,95 \%$ CI 0.5-2.05); however, during the 1980s there was an excess risk to women (relative risk $2.64,95 \% \mathrm{CI}$ $1.3-5.3)$. The incidence in women increased during 
the study $\left(\chi^{2}=6.6, P<0.01\right)$. The risk in other ethnic groups could not be reliably assessed as the sex structure of the population is unknown.

A $\chi^{2}$ analysis of the age-specific incidence for different age groups was significant at $P<0.001$ and showed that people aged 16-25 were at increased risk. In Bangladeshis and West Indians there was no discernible peak. The distribution in Europeans was bimodal, a broad second peak occurring in people aged 56-75 years (Figure 2). Three Bangladeshis were aged 22 and the others 31 and 45 years.

\section{Incidence by disease site}

There was no statistical difference in disease distribution between Europeans and other ethnic

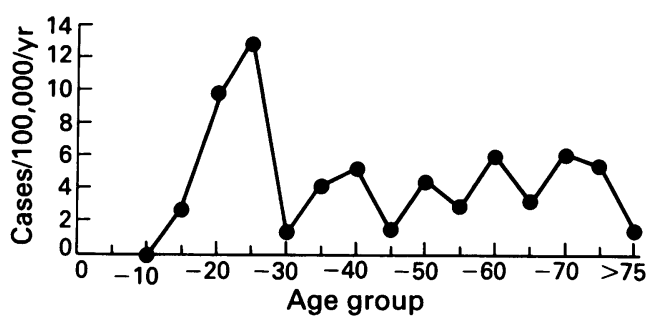

Figure 2 Age-specific incidence of Crohn's disease in Tower Hamlets for Europeans for 1972-1980 and 1981 - 1989. groups $\left(\chi^{2}=4.8\right.$, NS). The terminal ileum and colon were involved equally in Bangladeshis, Jews and other Europeans. The colon was affected in four of the five West Indians; the other patient had terminal ileal disease (Table II).

Overall, the age-specific incidence varied little with the site of disease $\left(\chi^{2}=11.1\right.$ for small bowel and 13.5 (NS) for large bowel disease). However, the age-specific incidence was significantly increased in people aged 21-25 years with terminal ileal disease. The incidence of ileal, colonic and mixed site $C D$ in Europeans tended to increase from the 1970 s to the 1980 s, but no change was significant $\left(\chi^{2}=0.6,0.3\right.$ and 0 , respectively).

\section{Frequency of complications}

The proportion of each ethnic group undergoing surgical resection was similar $\left(\chi^{2}=0.16, \mathrm{NS}\right)$. A total of 39 Europeans underwent surgical treatment for $C D$ and had a mean of 1.18 resections. Three Jews, two Bangladeshis and two other Muslims underwent one resection each. There were nine panproctocolectomies with ileostomies, the frequency in each ethnic group being similar.

The seven complications all occurred in Europeans, six were fistulae and one an adenocarcinoma. However, the complication rate did not differ in each ethnic group $\left(\chi^{2}=1.45, \mathrm{NS}\right)$.

Table II Disease distribution by ethnic group in Tower Hamlets

\begin{tabular}{lccccc}
\hline $\begin{array}{l}\text { Ethnic } \\
\text { group }\end{array}$ & $\begin{array}{c}\text { Terminal } \\
\text { ileum } \\
\text { only }\end{array}$ & $\begin{array}{c}\text { Colonic } \\
\text { only }\end{array}$ & $\begin{array}{c}\text { Small and } \\
\text { large } \\
\text { bowel }\end{array}$ & $\begin{array}{c}\text { Other small } \\
\text { bowel } \\
\text { only }\end{array}$ & $\begin{array}{c}\text { Perianal/ } \\
\text { proctitis } \\
\text { only }\end{array}$ \\
\hline Europeans & 29 & 30 & 15 & 2 & 4 \\
Jews & 3 & 2 & 1 & 1 & \\
Bangladeshis & 2 & 3 & 1 & & \\
Other & & 1 & &
\end{tabular}

There was no statistical difference in distribution of $\mathrm{CD}$ in each ethnic group.

Table III Method of diagnosis of Crohn's disease in Tower Hamlets 1972-1989 (\%)

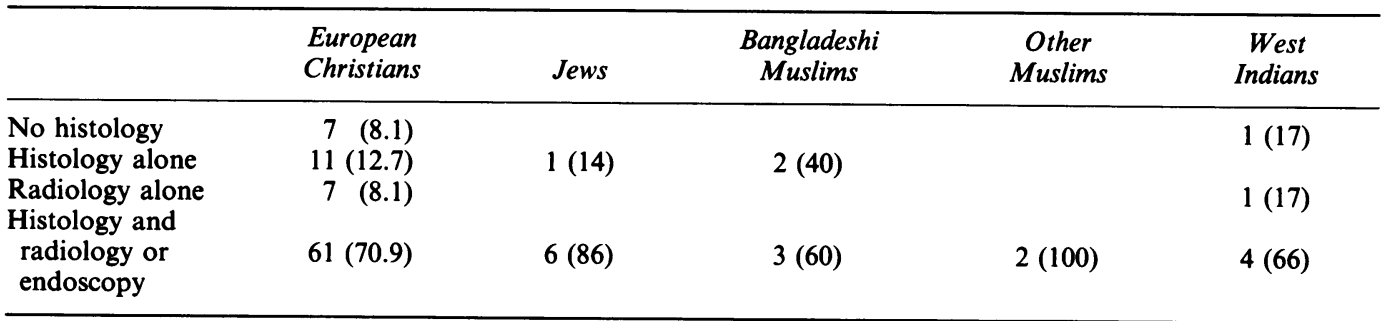

There was no difference in the method of diagnosis. 


\section{Method of diagnosis}

Many patients (33\%) were diagnosed using information from a combination of endoscopy, histology and radiology. There was no difference in the methods used to reach the diagnosis of CD $\left(\chi^{2}=20.8\right.$, NS) (Table III). All patients studied met similar diagnostic criteria. The mean delay in diagnosis in Europeans was 11.3 months (s.d. 18.5) and in Bangladeshis 23 months (s.d. 31.3) $(t=1.48$, NS).

\section{Discussion}

This is the first study of Crohn's disease in Bangladeshis in Britain. The community studied represents approximately $20 \%$ of the British population. ${ }^{31,36}$ The mean standardized incidence of Crohn's di- sease is 1.7 cases $/ 10^{5} /$ year. This appears to be low, but does not differ significantly from that in Europeans in Tower Hamlets, 4.1 cases/105/year.

The lack of statistical difference should be viewed with caution, the relatively small Bang- of ladeshi population means the wide confidence intervals of the Bangladeshi incidence engulf those of the European incidence. A similar Bangladeshi incidence from a larger study population would have given a statistically significant difference. Furthermore, the addition of one extra, or one less, Bangladeshi case could change the incidence by approximately $0.5 / 10^{5} /$ year. The study lacks the statistical power to detect a real difference.

The crude incidence in Jews ( 4.4 cases $/ 10^{5} /$ year) and standardized incidence in West Indians (3.6 cases $/ 10^{5} /$ year) is also similar to that of Europeans in Tower Hamlets and other series (Table IV).

Table IV Published data on incidence of CD

\begin{tabular}{|c|c|c|c|c|}
\hline Area of study & Duration & No. of cases & $\begin{array}{c}\text { Incidence } \\
\text { (cases } / 10^{5} / \text { year) }\end{array}$ & \\
\hline \multicolumn{5}{|l|}{ United Kingdom } \\
\hline Cardiff $^{1,2}$ & $1934-1977$ & 407 & 4.8 (1970s) & \\
\hline Derby 3,21 & $1951-1985$ & 225 & & 8 \\
\hline 1. South Asians & & 6 & 4.4 (1980s) & ஜृ \\
\hline 2. Others & & 219 & 7.5 (1980s) & ڤે \\
\hline 3. West Indians & $1976-1985$ & 5 & $4.5-5.6$ & $\stackrel{0}{\partial}$ \\
\hline Gloucester $^{4}$ & $1966-1970$ & 19 & 1.5 & \\
\hline Nottingham ${ }^{5}$ & $1958-1972$ & 144 & $3.6(1970 \mathrm{~s})$ & \\
\hline NE Scotland ${ }^{6}$ & $1955-1968$ & 166 & $2.2(1960 \mathrm{~s})$ & \\
\hline N Ireland ${ }^{7}$ & $1966-1981$ & 440 & 1.83 & \\
\hline Leicestershire & $1972-1989$ & 609 & & \\
\hline 1. Europeans & & 581 & $4.7(1980 \mathrm{~s})$ & \\
\hline 2. South Asians & & 28 & 3.1 (1980s) & \\
\hline Tower Hamlets & $1972-1989$ & 99 & & \\
\hline 1. Europeans & & 80 & $4.2(1980 \mathrm{~s})$ & \\
\hline 2. Bangladeshis & & 5 & $2.2(1980 \mathrm{~s})$ & \\
\hline 3. West Indians & & 5 & 3.6 (1980s) & \\
\hline \multicolumn{5}{|l|}{ Denmark } \\
\hline Copenhagen $^{8}$ & $1962-1978$ & 227 & $2.7(1970 \mathrm{~s})$ & \\
\hline Faroe Islands 9 & $1981-1988$ & 66 & 3.6 & \\
\hline \multicolumn{5}{|l|}{ Finland ${ }^{10}$} \\
\hline Helsinki & $1975-1985$ & 193 & $3.0(1980 \mathrm{~s})$ & \\
\hline \multicolumn{5}{|l|}{ Germany" } \\
\hline Tubingen Co. & $1970-1984$ & 828 & $4.0(1980 \mathrm{~s})$ & \\
\hline Iceland $^{12}$ & $1950-1979$ & 33 & 0.9 & \\
\hline \multicolumn{5}{|l|}{ Netherlands ${ }^{13}$} \\
\hline Leiden & $1979-1983$ & 210 & 3.9 & \\
\hline \multicolumn{5}{|l|}{ Norway } \\
\hline North $^{14}$ & $1983-1986$ & 82 & 5.8 & \\
\hline West $^{15}$ & $1984-1985$ & 86 & 5.3 & \\
\hline \multicolumn{5}{|l|}{ USA } \\
\hline New York ${ }^{16}$ & $1973-1986$ & 960 & $3.9(1980 \mathrm{~s})$ & \\
\hline Minnesota $^{17}$ & $1943-1982$ & 103 & 3.8 & \\
\hline
\end{tabular}


All but eight of the 2,800 potential cases of inflammatory bowel disease were reviewed. All were Europeans. Based on the relative incidence of $\mathrm{CD}$, proctitis and ulcerative colitis, ${ }^{27}$ the inclusion of these cases might be expected to yield three additional cases of $\mathrm{CD}$, three of UC and two of proctitis. This would not lead to a significant increase in the incidence of CD in Europeans (3\%).

As in other reports, ${ }^{1,3,7,8,10-12,16,17}$ the incidence in each ethnic group and in all anatomical sites tended to increase with time, though not significantly. The risk to men and women was similar during the 1970s, but increased significantly in European women during the 1980s, a finding not observed in other studies. In adults the risk of small bowel CD tended to fall with age. We have confirmed a bimodal age distribution in Europeans., ${ }^{3,7,10,12-15}$ Disease distribution and resection rates were similar in each ethnic groups, a finding noted in the Leicester study of Gujaratis and Punjabis. ${ }^{25}$

Reports from Asia suggest CD is uncommon. Gupta, in India, collected 44 cases over 10 years. ${ }^{19}$ In a study of referrals to mission hospitals in Bangladesh, CD was less common than UC. ${ }^{21}$ In the only epidemiological study from Asia, the incidence of CD in Kuwait was $0.5 / 10^{5} /$ year, based on 14 cases. $^{20}$

The possibility that ' $C D$ ' is abdominal tuberculosis, and vice versa, should not be overlooked. ${ }^{41-44}$ The demonstration of caseating necrosis or the culture of acid-alcohol fast bacilli are the yardsticks against which other investigations have to be measured.$^{45}$ Despite the difficulties the conditions can be differentiated with care. ${ }^{46}$ We have performed a parallel study of abdominal tuberculosis in Tower Hamlets to minimize the risk of misdiag- nosing either condition. The incidence of abdominal tuberculosis in Bangladeshis is 7.7 cases $/ 10^{5}$ year $^{33}$ and does not differ significantly from that of $C D$ $\left(\chi^{2}=0.5, \mathrm{NS}\right)$. This finding confirms the need to maintain a high index of suspicion that the diagnosis may be tuberculosis in Bangladeshis presenting with symptoms which in Europeans would be thought to be Crohn's disease.

The cause of Crohn's disease is unknown. The incidence in Bangladeshi and Europeans appears similar, but this may reflect the limited power. The actual number of cases is small and should be interpreted with care. Further studies are needed to measure the incidence of Crohn's disease in Bangladeshis and contrast it with the incidence values in other South Asian and Europeans communities. The dietary and social habits, and genetic differences between people of these ethnic groups may elucidate their risk factors and increase our understanding of the aetiology of Crohn's disease.

\section{Acknowledgements}

We thank the British Digestive Foundation and National Association for Colitis and Crohn's disease for their support of Dr Jayanthi and the Hilden Charitable Trust for supporting Dr Probert. We wish to thank Dr R. Newcombe, Senior Lecturer in Medical Statistics and Computing, University College of Wales, for his advice. We also thank the consultants of the Royal London Hospital, St Andrew's Hospital and St Mark's Hospital for allowing us to study patients under their care. We are grateful for permission to use records held by Dr K. Wilkinson and Dr J. Ritchie at St Mark's Hospital. Finally we would like to thank the Tower Hamlets Borough Council and Jewish Board of Deputies for their assistance in gathering population data.

\section{References}

1. Mayberry, J.F., Rhodes, J. \& Hughes, L.E. Incidence of Crohn's disease in Cardiff between 1934 and 1977. Gut 1979, 20: $602-608$.

2. Rose, J.D.R., Roberts, G.M., Williams, G., Mayberry, J.F. \& Rhodes, J. Cardiff Crohn's disease jubilee: the incidence over 50 years. Gut 1988, 29: 346-351.

3. Fellows, I.W., Freeman, J.G. \& Holmes, G.K.T. Crohn's disease in the City of Derby, 1951-1985. Gut 1990, 31: $1262-1265$.

4. Tresadern, J.C., Gear, M.W.L. \& Nicol, A. An epidemiological study of regional enteritis in the Gloucester area. Br J Surg 1973, 60: 366-368.

5. Miller, D.S., Keighley, A.C. \& Langman, M.J.S. Changing patterns in epidemiology of Crohn's disease. Lancet 1974, 2 . 691-693.

6. Kyle, J. An epidemiological study of Crohn's disease in North-east Scotland. Gastroenterology 1971, 61: 826-833.

7. Humphreys, W.G., Brown, J.S. \& Parkes, T.G. Crohn's disease in Northern Ireland - a retrospective study of $\mathbf{4 4 0}$ cases. Ulst Med J 1990, 59: 30-35.

8. Binder, V., Both, H., Hansen, P.K., Hendrisken, C., Kreiner, S. \& Torp-Pedersen, $K$. Incidence and prevalence of ulcerative colitis and Crohn's disease in the County of Copenhagen 1962-1978. Gastroenterology 1982, 83:

9. Roin, F. \& Roin, J. Inflammatory bowel disease of the Faroe Islands, 1981-1988. Scand J Gastroenterol 1989, 24 (Suppl 170): 44-46.

10. Halme, L., von Smitten, K. \& Husa, A. The incidence of Crohn's disease in the Helsinki Metropolitan Area during 1975-1985. Ann Chir Gynaecol 1989, 78: 115-119.

11. Daiss, W. \& Lorenz-Meyer, K. Epidemiology of inflammatory bowel disease in the County of Tubingen (West Germany). Scand J Gastroenterology 1989, 24 (Suppl 170): 39-43.

12. Bjornsson, $\mathbf{S}$. Inflammatory bowel disease in Iceland during a 30 year period, 1950-79. Scand J Gastroenterology 1989, 24 (Suppl 170): 47-49.

13. Shivananda, S., Pena, A.S., Nap, M. et al. Epidemiology of Crohn's disease in Regio Leiden, The Netherlands. Gastroenterology 1987, 93: 966-974.

14. Kildebo, S., Breckan, R., Nordgaard, K., Burhol, P.G. \& Jorde, R. The incidence of Crohn's disease in Northern Norway from 1983 to 1986. Scand J Gastroenterol 1989, 24: $1265-1270$.

15. Haug, K., Schrumpf, E., Halvorsen, J.F. et al. Epidemiology of Crohn's disease in Western Norway. Scand J Gastroenterol 1989, 24: 1271-1275. 
16. Stowe, S.P., Redmond, S.R., Stormont, J.M. et al. An epidemiological study of inflammatory bowel disease in Rochester, New York. Gastroenterology 1990, 98: 104-110.

17. Gollop, J.H., Phillips, S.F., Melton, L.J. \& Zinsmeister, A.R. Epidemiological aspects of Crohn's disease: a population based study in Olmstead County, Minnesota, 1943-1982. Gut 1988, 29: 49-56.

18. Barton, J.R., Gillon, S. \& Ferguson, A. Incidence of inflammatory bowel disease in Scottish children between 1968 and 1983: marginal fall in ulcerative colitis, three-fold rise in Crohn's disease. Gut 1989, 30: 618-622.

19. Gupta, R.S., Chatterjee, A.K., Roy, R. \& Ghosh, B.N. A review of the results of treatment of 44 cases of Crohn's disease. Indian J Surg 1962, 24: 787-805.

20. Al-Nakib, B., Radhakrishnan, S., Jacob, G.S., Al-Lidawi, H. \& Al-Ruwaih, A. Inflammatory bowel disease in Kuwait. Am J Gastroenterology 1984, 79: 191-194.

21. Probert, C.S.J., Mayberry, J.F. \& Mann, R. Inflammatory bowel disease in the rural Indian Subcontinent: a survey of patients attending mission hospitals. Digestion 1990, 47: 42-46.

22. Fellows, I.W., Mayberry, J.F. \& Holmes, G.K.T. Crohn's disease in West Indians. Am J Gastroenterol 1988, 83: 752-755.

23. Das, S.K. \& Montgomery, R.D. Chronic inflammatory bowel disease in Asian immigrants. Practitioner 1978, 221: 747-749.

24. Keshavarzian, A., Gupta, S., Saverymuttu, S.H. \& Hodgson, H.J.F. Are there ethnic differences in inflammatory bowel disease? Indian J Gastroenterology 1986, 5: 95-97.

25. Jayanthi, V., Probert, C.S.J., Pinder, D., Wicks, A.C. \& Mayberry, J.F. Epidemiology of Crohn's disease in Indian migrants and the indigenous population in Leicestershire. $Q J$ Med 1992, 82: 125-138.

26. Probert, C.S.J., Jayanthi, V., Pinder, D., Wicks, A.C. \& Mayberry, J.F. An epidemiological study of ulcerative proctocolitis in Indian migrants and the indigenous population of Leicestershire 1972-1989. Gut 1992, 33: 687-693.

27. Jaynathi, V., Probert, C.S.J., Pollock, D.J., Baithun, S.I., Mayberry, J.F. \& Rampton, D.S. Reduced incidence of ulcerative colitis and proctitis in Bangladeshi migrants in Britain. Digestion (in press).

28. Carey, S. \& Shukur, A. A profile of the Bangladeshi community in East London. New Community 1985, 12: 405.

29. Ballard, R. \& Ballard, C. The Sikhs: The development of South Asian settlements in Britain. In: Watson, J.L. (ed.) Between Two Cultures. Blackwell, Oxford, 1977.

Appendix 1: Epidemiology of IBD patient data

Name No.

DOB .../.../... Age . yr Sex

Race ..... Religion Place of birth

Address Tel

(Address at diag GP

Crohn's

Date onset ..../..../.../

U.C.

Date presentation ..../.../....
Date diagnosis ..../.../....
History diarrhoea
blood
mucus
pain

Dif
Dif
$\begin{gathered}\text { History diarrhoea } \\ \text { blood } \\ \text { mucus } \\ \text { pain }\end{gathered}$

30. Harrison, P. The lift of cities. N Scientist 1974, ??: 599-604.

31. Haskey, J. The ethnic minority populations resident in private households - estimates by county and metropolitan $\varrho$ districts of England and Wales. Pop Trends 1991, 63: 22-35. $५$

32. Lennard-Jones, J.E. Classification of inflammatory bowel $\Rightarrow$ disease. Scand J Gastroenterol 1989, 24 (Suppl 170): 2-15.

33. Sheldon, C., Probert, C.S.J., King, K. et al. Incidence of 0 abdominal tuberculosis in Bangladeshis and Europeans in the London Borough of Tower Hamlets. Tubercle Lung Dis (in press).

34. OPCS. The Registrar Generals Statistical Review of England and Wales 1971. HMSO, London, 1972.

35. OPCS. 1981 Census Report. HMSO, London, 1982.

36. Projection of the Bangladeshi Population by Neighbourhood $\vec{\circ}$ in Tower Hamlets, 1981 -91. London Research Centre, 1988.

37. Haskey, J. The ethnic minority populations of Great Britain estimates by ethnic group and country of birth. Pop Trends 1990, 59: 35-38.

38. Armitage, P., Berry, G. (eds). Statistical Methods in Medical Research, 2nd ed. Blackwell, Oxford, 1987.

39. Gardner, M.J. \& Altman, D.G. (eds). Statistics with Confidence. British Medical Journal, London, 1989.

40. Langman, M.J.S. The Epidemiology of Chronic Digestive Disease. Edward Arnold, London, 1979.

41. Burke, G.J. \& Zafar, S.A. Problems in distinguishing tuberculosis of bowel from Crohn's disease in Asians. Br Med J 1975, 4: 395-397.

42. Devanesan, J.D., Sable, R.A., Pitchumoni, C.S., Lev, R. \& Zapiach, L. Segmental tuberculosis of the colon mimicking carcinoma. Arch Surg 1980, 115: 90-91.

43. Carr-Locke, D.L. \& Findlay, D.B.L. Radiological demonstration of colonic aphthoid ulcers in a patient with intestinal tuberculosis. Gut 1983, 24: 453-455.

44. Humphreys, C., Wake, P.N. \& Walker, R., Jejunoileg tuberculosis; a diagnostic pitfall in Crohn's disease. $\mathrm{Br} \mathrm{Med}$ 1980, 3: 118-119.

45. Hoon, J.R., Dockerty, M.B. \& Pemberton, J.D.J. Ileocaech tuberculosis including a comparison of this disease wi non-specific regional enterocolitis and noncaseous tuberculated enterocolitis. Int Abstr Surg 1950, 91: 417-440.

46. Tandon, H.D. \& Prakash, A. Pathology of intestinal tuberculosis and its distinction from Crohn's disease. Gut 1972, 13: 260-269.
Histol. extra colonic granulomas skip lesions lymphoid aggregates

Endosc. discontinuous/strictures

Radiol. skip lesions strictures/fibrosis fistulae abscesses

Infection (micro) Ischaemia (path/history)

\section{FINAL DIAGNOSIS}

Histol. inflammation no granluoma

Endosc continuous Barium Econtinuous

\section{Exclusions}

Infection (micro)

Irradiation (history) Ischaemia (path/side) Crohn's-upper/anal

\section{,

